\title{
What evidence do we need for evidence based medicine?
}

\author{
Julian Tudor Hart
}

\begin{abstract}
This Cochrane
lecture was

presented at the

Society for Social Medicine Meeting in September 1997 at York University
\end{abstract}

\section{Summary}

As presently understood, evidence based medicine aims to advance practice from its traditional unverifiable mix of art and science to rational use of measurable inputs and outputs. In practice, however, its advocates accept uncritically a desocialised definition of science, assume that major clinical decisions are taken at the level of secondary specialist rather than primary generalist care, and ignore the multiple nature of most clinical problems, as well as the complexity of social problems within which clinical problems arise and have to be solved. These reductionist assumptions derive from the use of evidence based medicine as a tool for managed care in a transactional model for consultations. If these assumptions persist, they will strengthen reification of disease and promote the episodic output of process regardless of health outcome.

We need to work within a different paradigm based on development of patients as coproducers rather than consumers, promoting continuing output of health gain through shared decisions using all relevant evidence, within a broader, socialised definition of science. Adoption of this model would require a major social and cultural shift for health professionals. This shift has already begun, promoted by changes in public attitudes to professional authority, changes in the relation of professionals to managers, and pressures for improved effectiveness and efficiency which, contrary to received wisdom, seem more likely to endorse cooperative than transactional clinical production. Progress on these lines is resisted by rapidly growing and extremely powerful economic and political interests. Health professionals and strategists have yet to recognise and admit the existence of this choice.

\footnotetext{
International Section, Department of Primary Health Care, Royal Free Hospital Medical School, London J T Hart

Correspondence to: Dr J T Hart, Gelli Deg, Penmaen, Swansea $\mathrm{SA} 32 \mathrm{HH}$.
}

\section{Cochrane and the rebirth of social medicine}

It is now 25 years since publication of Cochrane's Effectiveness and Efficiency. ${ }^{1}$ This work summarised his main achievement, a rediscovery of what virtually everyone accepts today, but few did in 1973: that medical practice is a mode of production of value, with measurable inputs and outputs. This was a huge step forward from medical practice as partly art or religion, providing shelter whenever practice failed to match the qualities of the science from which it derived its authority. $\mathrm{He}$ opened a huge range of new possibilities we are only beginning to explore. It is a great honour for me, one of his more wayward apprentices, to give this lecture to so distinguished an audience.

The ideas in Effectiveness and Efficiency were a rediscovery. Objective measurement of clinical output has been available ever since doctors claimed to change the course of illness. They had only to dare to test this claim by controlled experiment. Generations which thought little of putting entire cities to the sword would have had few scruples about simple human experiments. If this question was seldom seriously addressed, and the few who did were always isolated by their peers, this was because few doctors or patients were willing to risk destruction of hope by seeking a serious answer, when hope, the placebo effect, was almost the only weapon they had.

Effectiveness and Efficiency was conceived at exactly the right time. Starting around the mid-1930s, a growing minority of clinicians began to use science not only as a source for new weapons against disease, but to measure how far those weapons were effective. By the early 1950s, when Cochrane began his pioneering studies in the Rhondda Fach, enough medical practice was real for its more courageous practitioners to discard their old armour of mutual reassurance and deception, built jointly by doctors and patients around the placebo effect. By the 1970 s, medical care the world over was becoming too effective, too expensive, and too potentially profitable for investment to be left to an unaccountable profession. The state, and socioeconomic interests controlling it, were no longer willing to let medical professionals set the aims and rules of a game which others had to pay for, or to let them take profits as self employed entrepreneurs when all this might be done more effectively and profitably by corporate employers. Nor could they allow patients to believe that any major part of the economy could work efficiently based on gift rather than commodity relationships, defying all rules of the market Cochrane $^{2}$ and $\mathrm{McKeown}^{3}$ were early voices in a neoliberal chorus, questioning all traditional 
claims of medical professionalism. They ignored the alternative vision offered by Titmuss, despite his equally rigorous but entirely different body of evidence that it might be cheaper and more efficient to give than to sell. ${ }^{4}$ In the populist form offered by Illich, ${ }^{5}$ they captured the imagination of rebellious youth for an essentially consumerist view of the future. Joined with the rebirth of economic neoliberalism, resurrection of $\mathrm{Hayek}^{6}$ and beatification of Friedman, ${ }^{7}$ they provided an ideological foundation for what in the 1990s became an international reform of state medical services in the image of commodity-manufacturing industry, led by Alain Enthoven, ${ }^{9}$ the OECD, World Bank, and International Monetary Fund. Cochrane's book provided just what the new managers thought they needed.

Cochrane saw medical care as a verifiable productive process, and therefore a field suitable for application of economic theory. $\mathrm{He}$ never seems to have questioned the fundamental assumptions on which classical macroeconomic theory rests. These have neither explained nor predicted the behaviour of any real economy in 200 years, a weakness which compels its theoreticians to use computer models rather than empirical tests of the real world, ${ }^{10}$ a weak position for a discipline claimed as science. However, classical economic theory has three great subjective merits. Firstly, since it proclaims that markets can manifest their superiority to any guiding human intelligence only if they have no such guidance, its failure to provide a predictive theory is impossible to fault within its own terms. Secondly, it legitimises wealth for winners and poverty for losers in a universal struggle for existence attributed to nature rather than a particular kind of society at a particular time in history. As most of its more articulate critics see themselves closer to winners than losers in their personal lives, there is much scope for observer bias. And finally, like the prison system, though everyone knows it doesn't work, nobody seems to have come up with a more plausible alternative. Though Cochrane took pride in iconoclasm, these icons he left unchallenged.

\section{A currency for rational health economics?}

In Effectiveness and Efficiency, he speculated on the problems entailed in achieving a single currency to measure widely different clinical activities. This seemed the only way to quantify and thus compare outputs in economic terms. As he wrote in Effectiveness and Efficiency:

"If the saving of a man's life aged 20 and restoring normal expectation of life is 100, what number should be assigned to the care of a severe schizophrenic? Many people have a reasonable dislike of quantifying value judgements, but I am now convinced it is necessary. I think, although the use of quantification is far ahead, the exercise is worthwhile, if only for the intellectual satisfaction of thinking something through to the end, to demonstrate the incredible difficulties inherent in the two stages, and to determine the direction in which to aim." 11
As he anticipated, his view was perceived by clinicians as inhuman, and therefore unworkable in an industry handling human lives. As our mutual friend Richard Doll said two years later:

"We can estimate the cost of a disability or saving a life, but we cannot express the value of the product in economic terms in such a way that we can compare the prevention of mental deficiency in a child with saving the lives of so many men and women in their 60s. Decisions have to be made subjectively, and in practice are usually the result of a judicious balance of competing pressures. It is a field in which gardening is real and botany is bogus." 12

All Cochrane's work implied that clinical activity ought to produce value as health gain, though he found little evidence that it actually did so. ${ }^{13} \mathrm{He}$ never seems to have considered the possibility that wealth might be created in any way other than as commodities. Though all commodities must have perceived value (otherwise nobody would buy them), not all values are commodities. In fact most people find that their highest values are difficult or impossible to create or distribute in commodity form, a serious problem for a society where hardly anybody who is anybody dares to imagine any other way of producing or sharing the social product. Commodity production absolutely requires a pricing system with common or convertible currency. If you accept commodity production, you must devise a currency. But if no such rational currency can exist - that is, if attempts to create one lead to nonsensical results in human terms-you must devise some different way of measuring and sharing costs and distributing the results of value production, perceived in terms other than a commodity transaction. This possibility seems not to have occurred either to Cochrane or to any of the army of health economists, health care managers, or other value free methodologists and thinkers of the unthinkable who used his work as their ideological foundation for the "reform" of state medical services on the lines of commodity production.

Evidence based medicine ${ }^{14}$ seems now to provide the ideological framework within which these international "reformers" of state medical care can best operate. It aims to use the best available evidence from meta-analyses of randomised controlled trials as the principal basis for clinical strategies and guidelines for practice in an attempt to close the gap between rational theory and irrational practice.

\section{Clinical decisions within consultations are initiating units of production}

Clinicians do prefer being real gardeners to being quasi-botanists, so I found Richard Doll's aphorism attractive in 1973. But did patients ever fancy being crops of flowers or vegetables? We need to think more carefully about the exact nature of clinical production at its most basic and initiating level, decisions within consultations in primary care. Values exist at the end of a consultation which did not exist at the beginning. These outputs are better understanding of patients' problems and first 
steps toward their containment or resolution. If health economists want to improve the real world as a place for real people to live in, they must take account of how these outputs can be produced most efficiently, and how the main actors in the consultation relate to each other in this productive process.

For the NHS as an industry, the most important determinants of cost are not exceptional situations like that of Child $B,{ }^{15}$ which almost monopolise media attention. Nor are they common procedures such as hip replacement, hysterectomy, or initiation of lifelong treatment to control blood pressure, which preoccupy health economists. The most important determinant of costs is the culture within which both doctors and patients take decisions about the very nature of the problems patients present and rational choice of pathways for their solution.

A huge proportion of clinical effort is currently invested not in solving problems people actually have, or are even likely to have, but in gathering negative evidence about what they don't have. Representative figures are astonishing. Looking at patients referred to a specialist medical outpatient department in $1952 .{ }^{16}$ Gottlieb found 39\% had no evidence of organic disease. Repeating this in 1963, this proportion was almost the same at $40 \% .^{16}$ Thirty years later, roughly half of all patients presenting to Dutch general medical outpatient clinics were found to have no detectable organic abnormalities that could account for their symptoms. ${ }^{17}$ Of course, suspected organic disease does have to be investigated, but this rational component cannot account for the monstrous size of this generally negative activity.

Medically unexplained physical symptoms are a huge drain on resources, ${ }^{18}$ but larger still are the costs of somatized illness accepted as disease by giving patients the supposed benefits of doubt through superfluous interventions, medical or surgical. Many of our commonest procedures, for example dilatation and curettage or hysterectomy for excessive menstrual bleeding, cholecystectomy for painless but apparently troublesome gall stones, spinal nerve root decompression procedures for back pain, or initiation of antihypertensive drugs, tranquillisers or hypnotics, are essentially discretionary. They depend on interpreting personally unique patterns of illness, rather than recognising generalised patterns of disease. In all care systems and in all cultures, huge differences in rates for such procedures suggest the operation of social rather than biological factors, for both professionals and patients. Though intervention rates for these procedures are generally at least $50 \%$ smaller and also more uniform in the NHS than in fees-promoted systems, like those in USA and Germany, ${ }^{19}$ they still offer huge scope for rational reduction, with potential benefit for patients as well as reduced costs.

As a characteristic example, take the problem of excessive menstrual loss, thoroughly researched by Angela Coulter. Though decisions for or against operative interventions have always appeared to be taken by hospital based specialists, her work shows the course is already set, before referral, by decisions taken in primary care. ${ }^{20}$ About one third of all UK women of reproductive age complain of excessive menstrual bleeding, and this is the main presenting symptom in $12 \%$ of referrals to outpatient gynaecology departments. ${ }^{21}$ There is virtually no correlation between patients' subjective impressions of menstrual loss, the number of towels or tampons they use, and the actual amount of blood they lose, ${ }^{22}$ probably because this is a personal matter with no standard for comparison. For research in this field, the consensus threshold for menorrhagia is a monthly loss of $80 \mathrm{ml}$ blood. Actual measurement of loss, though relatively simple, is rarely performed even by specialists, but wherever these measurements have been made, only about half of patients referred are above this threshold.

This would seem an excellent opportunity for evidence based medicine to close a costly gap between what doctors know, or ought to know, and what they do. However, before rushing in with guidelines, even salespersons for evidence based medicine might consider why so many rational people behave in this irrational way. Why don't specialists assess patients routinely to see whether they actually need any treatment at all for menorrhagia, other than a clear explanation of how they compare with other normal women, and time to explore the many other problems most middle aged women have which constitute their own unique pattern of illness, rather than a standard pattern of disease? The main answer seems to be that they do not believe patients would accept this verdict. A small study of 17 such women at the John Radcliffe Hospital, with monthly blood losses between 15 and 60 $\mathrm{ml}$, found that three years after being told their blood loss was normal and did not need treatment, 14 had accepted this, two were taking medication, and one had managed to get herself a hysterectomy. ${ }^{23}$ Though this suggests a more than $80 \%$ success rate, there is other evidence that many such women feel happier after a hysterectomy. Coulter ${ }^{24}$ found that of patients who had complained of mild to moderate menorrhagia, $83 \%$ who had had hysterectomies were satisfied with their treatment compared with only $45 \%$ of those treated by medication. Results were only marginally different for women complaining of severe bleeding. As these cases included women not referred, but treated medically by their GPs, even more than half of them probably had menstrual losses within the normal range.

Hysterectomy removes more than a uterus. Some women seem to want this collateral damage, with its assurance of an end to reproduction, and perhaps occasionally the possibility of dignified retreat from an unsatisfactory sexual role: but many don't. "To study the indications for hysterectomy is to study the interface between medicine and society". ${ }^{25}$ Hysterectomies are done three times more readily in the USA than in the UK, twice as readily in Australia and Canada, and in the USA over half of all women lose their uterus in 
their lifetime. In these lands of fees and consumer sovereignty, women seem to demand more surgery, not less. On the other hand, rates in Norway are about half those in UK, and Norwegian women seem none the worse for it. $^{26}$

This situation seems unlikely to respond well to guidelines. As in most cases with wide scope for different decisions, the nub of the problem is not that doctors lack good information, but that they see good reasons to ignore it. Patients, on the other hand, certainly do lack information. Doctors are learning only slowly how to share it with them, and how much more effective and efficient consultations can be if patients are fully informed about medical evidence, if doctors are fully informed about patients' evidence and if decisions are shared.

Even within the body of evidence which evidence based medicine nominally accepts, there seem to be whole continents of knowledge which though long discovered, are still ignored. The somatised effects in adults of sexual and physical abuse during childhood are apparently indistinguishable. Joint prevalence of both forms of abuse seems to be about $25 \%$ in all populations hitherto studied. ${ }^{27}$ If, as a child, the only way you can complain about being sad or frightened is to have a headache, palpitation, or other symptom suggesting somatic illness, that is how you learn to complain. ${ }^{28}$ Such symptoms are real, and in searching for explanations, patients may find fears of cancer, which they don't have, less frightening than fears of their own stories, which they do have. If doctors don't want to hear these, or don't have time to hear them, and prefer to pass responsibility to specialists even less likely to search outside received medical categories, considering only negative tests or benefit of the doubt interventions for organic disease, the stage is set for massive inefficiencies in the way health services are used. Even the most patient oriented doctors are ineffective and inefficient proxies for their patients' own wants and needs. Patients must speak and act for themselves, but fundamental changes in training for and researching of primary care are necessary for this to happen. I practised in one community for 30 years, containing many personal friends, many opportunities to gain knowledge informally, and with a family who shared social and school life with everyone else. In all that time, fewer than 10 cases of childhood abuse came to my notice, and no abuser ever consulted about his or her problem. We still live in a society so skilled at sweeping skeletons under the carpet, it's a wonder anyone can walk on it without feeling the bones. Evidence of this sort is ignored not because it is small, but because it is too big, and its implications too monstrous, to fit the fairy tales on which we've been reared.

For internal medicine, about $85 \%$ of final diagnoses are reached just from what patients tell us. We add only $7 \%$ by examining them and another $8 \%$ by technical investigations. ${ }^{29-30}$ For almost all treatments outside hospital, where patients can make their own decisions, their compliance is essential, and this in turn depends on understanding. These facts alone guarantee that patients must function as co-producers rather than consumers, but professional culture still perceives doctors as the only source of evidence, and this obstructs development of more effective and efficient shared decisions.

Serious study of consultations began with Byrne and Long in the 1970 s, ${ }^{31}$ with little added since the 1980 s. Though few question the reality of at least potential health gain as a product of consultations, it is notoriously difficult to measure. A reasonable proxy is patient satisfaction..$^{32-34}$ What patients initially want is seldom exactly what they need, but unless wants and needs come voluntarily together, output will fail. The main determinant of successful output from consultations is therefore agreement between doctors and patients on the main problems presented. In USA, Barbara Starfield found doctors and patients agreed on this in only about half of all visits. ${ }^{35}$ Another study found that in consultations for bodily complaints, doctors and patients agreed on the nature of main problems in $75 \%$ of cases, but for those mainly concerning the mind, agreement fell to $6 \% .^{36}$ Beckman found that doctors gave patients an average of 18 seconds to tell their story before interrupting and diverting them to doctor-preferred topics. ${ }^{37}$ In Canada, McWhinney found $54 \%$ of patients' complaints and $45 \%$ of their concerns were not being elicited. ${ }^{38}$ In the UK, David Tuckett found no difference between Balint-trained GPs committed to patient centred care, and randomly sampled controls without such training who were not. Neither group showed any interest in eliciting patients' opinions. ${ }^{39}$

The inefficiency of transactional consultations has therefore been staggering, and this has certainly had huge though unmeasured consequences for how primary gatekeepers label problems, how they select for referral to specialists, and which specialised pipelines they choose. Can this change? Given some important spiritual and material preconditions, it certainly can. By the late 1990s, in British practices linked to academic departments of primary care, with staff trained to appreciate the intelligence and imagination of their patients, and caseloads low enough to allow sensitive work, wants perceived by patients and needs perceived by staff coincided over roughly $80 \%$ of measured variables. ${ }^{40}$ This suggests that GPs, or at least those with academic links, are ready to move toward more cooperative consulting styles.

If all problems were equally important, equally difficult, and incurred equal costs for solution; if all primary health workers had the caseloads typical of practices involved in undergraduate teaching; and if nobody profited from promotion of clinical process regardless of health outcome, this picture would be reassuring. Unfortunately, none of these preconditions is met for most people in most places most of the time.

Cooperative styles of consultation tend to be absent for exactly those patients for whom they are most necessary, namely those with problems most difficult to fit into the simple 
categories of organic disease doctors have been trained to recognise and prefer. Full use of all sources of evidence cannot occur within very short consultations. ${ }^{41}$ Subtler needs cannot be sought until immediate wants have been addressed and minimal expectations met. GPs who try to introduce more patient oriented methods within the traditional booking intervals of 5 minutes, and mean consultation times of 6-8 minutes, find most patients prefer ordinary dogmatic paternal care. ${ }^{42}$ Though everyone has always known, and meticulous research by John Howie ${ }^{43}$ has confirmed, that a mean consultation length around 10 minutes is a precondition for accurate joint decisions in primary care, we still have not reached that target, proposed by Buchan and Richardson in $1971 .^{44}$ The most recent figure suggests an average around 9 minutes. ${ }^{45}$ Though few people with real power ever consult a GP, this is unlikely to be the main reason why governments and health economists have always refused to address consultation time as a real issue. A more powerful reason is their own definition of efficiency, namely higher throughput by fewer workers in shorter time. In commodity production, the first step toward higher efficiency or quality is not more time to do a job, but greater pressure on workers to meet targets. Contrary to the unsubstantiated assertions of The Economist, GPs spend little time on golf courses, with an average 42 hour working week excluding night and out of hours work. ${ }^{46}$ More time for consultations mainly depends on lower caseloads, larger, more diverse and more integrated practice teams, and relations between team members not bedevilled by entrepreneur status for GPs.

\section{A time to choose}

Managed care promises to raise patient power through consumerism. More uteruses might be removed more efficiently and with greater consumer satisfaction, other interventions might be similarly promoted and their unit cost reduced, and all procedures might become safer as they became more industrialised. As a body repair and redecoration service, the NHS might become more efficient. It would employ fewer people at higher salaries, and continuing anticipatory care would be delegated to unskilled body housers, feeders, and cleaners, paid minimum wages by corporate providers on contract. This is not a formula for rationalising demand, but for promoting demand at lower unit cost. Managed health care has emerged from USA, with the world's most irrational and, by all measures, least efficient health care system, but is now being exported around the world. This arises not from the foolishness of power holders, but from their perceived self interest. Health care is already big money. It promises a more golden future than any other commodity market, dealing with increasingly plausible promises to deliver life itself to whoever can pay for it-the ultimate commodity. In the world market crash of 1987, only investments in health care continued to gain value. Although about $20 \%$ of US citizens have no access to anything except emergency care, US care plans are now running out of customers, and are looking for new markets abroad. ${ }^{47}$

In this battle for world market shares, methodologies are not neutral, and this includes evidence based medicine. Different ideologies need and use different instruments and cultures. Kenneth Clark said his 1990 reforms were intended to make the NHS businesslike, not to turn it into a business. This view was endorsed by his chief executive Sir Duncan Nicholl, before he resigned to run BUPA. ${ }^{48}$ More convincingly, Richard Smith told $B M F$ readers the following year that "methods of business are essential in the NHS not because they are the methods of making profits but because they are the methods of running large organisations." Minister Frank Dobson's decision to retain most of the businessmen appointed by Conservative governments to trust boards. Trust managements must, he says, include enough people with experience of corporate organisations. No doubt that's true, but this experience might be of two kinds: of bossing, or of being bossed. Little thought seems to have been given to experience from below, though for any government seriously determined to shift NHS culture toward greater respect for patients and staff as people this seems very relevant.

Health services research suggests that using evidence from a much wider social as well as biological range, sharing this with patients, and encouraging them to participate in diagnostic and treatment decisions, produces better health outputs than above-down transactions - and at lower cost. ${ }^{50-51}$ Consultations of this kind, and the culture necessary to promote them, do not resemble business methods as experienced by employed people. From the smallest corner shop to the largest multinational corporation, business has one single ultimate and predominant aim, to maximise profit. The first means to this end is usually to maximise output and minimise labour time, and thus reduce unit cost of output. When managers experienced in commodity production for profit move into management of non-profit public services, their aim shifts from maximising profit to minimising costs, which they see not as wealth creating social investment, but a tax burden on wealth production in the larger economy. By far the largest cost component in the NHS is labour. Their natural strategy is therefore to shift the NHS as a whole from neighbourhood-serving, labour-intensive continued caring, to marketserving technology-intensive episodic curing. Their measurable product is process, not health outcome. Nor do businesses, large or small, bother with any nonsense about democracy. Despotism is accepted as necessary and normal, less as a rule than in the armed forces, but of the same nature, with commercial secrecy precluding any real culture of self critical openness. Much as politicians and economists affect to despise command economies at a national level, virtually all businesses run internally as command economies, with executives selected for ruthless dedication to profit 
for themselves and their shareholders, not for service to society.

There is in fact no valid external model for evidence based medical care of the sort I have described, because the NHS, in its pre-reform days, was the only major industry we had which produced value other than as a marketed commodity. The NHS was, and despite all "reforms" still tries to remain, an institution socially more advanced than the society it serves, based on gift relationships addressing human needs, rather than market driven trade. In the pre-"reform" NHS nobody seemed to know the cash cost of anything, and the whole system worked without internal pricing: but it did so at a lower proportion of gross national product than in any other fully industrialised country except Denmark, whose system closely resembled our own. If policies had ever been based on evidence or probability, the very idea of pushing business methods and attitudes into the public service culture of the NHS would have been unthinkable.

Hasty, thoughtless, insensitive clinical decisions which do not use all available and relevant biological knowledge are less efficient and more costly than unhurried, thoughtful, sensitive decisions which do. Ditto for relevant social knowledge about society as a whole. And ditto for social knowledge about this specific patient sitting here, with his or her unique illness, and probably unusual though perhaps not unique combination of diseases, usually (not occasionally) impossible to fit into any simple Procrustean bed of guidelines. The simplest and most obvious way to improve efficiency and contain costs in the NHS is to create optimal conditions for decisions of this kind, promoting more thoughtful and socially responsible joint judgements by professionals and patients, aiming at optimal solutions for their problems in human rather than economic terms. Experience suggests that optimal efficiency in human terms, reached by considering possible risks as well as possible benefits of all interventions, usually yields lower cost as a byproduct. Obviously there will be exceptional patients where optimal decisions in human terms may be extremely costly, but these are few. If we do not accept their exceptional costs, we cannot expect patients to trust us when we express scepticism about the latest breakthrough or desperate pilgrimage to America. Even when professionals generally behaved as if the NHS were their own condescending charity rather than a public service owned and shared by everybody, paternalist decisions uncorrupted by fees provided a thriftier service than any fee-driven market. Now that a critical mass of professionals seems ready to embrace ideas of participative democracy, we could look forward to an even more cost effective service.

But this is a real choice, between mutually exclusive alternatives. More time for primary decisions, more respect for primary health workers, more respect for the brains and imagination of patients, more development of patients as critical observers, measurers, and recorders of their own illnesses, is not compatible with business definitions of efficiency. It demands time, non-hierarchical teamwork, and respect for honest admission of our limitations, and the huge gap everywhere between what could be done using existing knowledge, and what actually is done using only fragments of that knowledge. This means that audit data and other evidence about performance cannot be used for performance related pay or to punish failure. In a cooperative economy, poor performance should imply remedial action, often additional researching, not penalties. Its health professionals must retain clinical and social autonomy, solving problems in their own way and acting as advocates for patients, workers retaining control of their product, a total denial of the industrialised production line.

Of course, such a cooperative gift economy still has to be managed. Managers will be needed to formulate budgets and either hold staff within them, or negotiate with regional or national authorities for greater resources, an ultimately political choice of priorities for al citizens. Clinicians and managers will from time to time disagree, because their socia functions, and their relations even within noncommodity production, are different. But even present experience shows that most managers can give up the business model, providing an alternative is available: indeed, many have moved into the NHS precisely because they found business culture intolerable. Business culture deifies process, reifies disease, embraces paranoid concepts of intellectual property and commercial secrecy, is unable to do anything without adding transactional cost, and demonises all disagreement, doubt or protest. It needs to be pushed back from whence it came, to the periphery of the NHS, to those necessary and inevitable points of contact with its surrounding more primitive culture, where human benefit is still only an erratic byproduct of search for profit.

"I need not remind you", wrote Florence Nightingale to Sir John MacNeill in 1857, "that what we get into scrapes for is not for saying what nobody believes and everybody says but for saying what everybody believes but nobody says." ${ }^{52}$ A democratised public service culture can only make headway against established and predominant market culture if we have a clear vision of the alternative, and a jealous love for it. The main outlines of such a vision already exist as a mass culture. Neither we nor our patients ever asked or voted for money changers to enter our temple, and we would see the back of them with relief. People who really care, and therefore count the human gains and human costs of their decisions, don' need to translate every decision into cash equivalents. If we really cared about people, the money would look after itself. That is a testable hypothesis, which I commend to this competent audience.

I thank Dr Jane MacNaughton and Professors Nigel Stott, Pau Wallace, Graham Watt for helpful advice.

1 Cochrane AL. Effectiveness and efficiency. London: Nuffield Provincial Hospitals Trust, 1971.

Hart JT. An assault on all custom: Cochrane's "Effectiveness and efficiency". Int $\mathcal{F}$ Health Services 1973;3:101 -4. 
3 Hart JT. Advancing backwards: McKeown's "The role of medicine". Milbank Memorial Fund Quarterly Health E Society 1977;55:383-8.

4 Titmuss RM. The gift relationship: from human blood to social policy. London: George Allen \& Unwin 1970.

5 Illich I. Medical nemesis: limits to medicine. London: Marion Boyars, 1976.

6 Hayek FA. The road to serfdom. Chicago: University of Chicago Press, 1944.

7 Friedman M, Friedman RD. Capitalism and freedom. Chicago: University of Chicago Press, 1962

8 Hart JT. $A$ new kind of doctor: the general practitioner's part in the health of the community. London: Merlin Press, 1988; 19-39.

9 Enthoven A. Theory and practice of managed competition in health care finance. New York: North Holland Publishing,

10 Ormerod P. The death of economics. London: Faber \& Faber, 1994.

11 Cochrane AL. Effectiveness and efficiency. London: Nuffield Provincial Hospitals Trust, 1971;77.

12 Doll WRS. Monitoring the National Health Service. $\mathcal{F} R$ Soc Med 1973;66:729-40.

13 Cochrane AL, St.Leger AS, Moore F. Health services "input" and mortality "output" in developed countries. $f$ Epidemiol Community Health 1978;32:200-5.

14 Sackett DL, Rosenberg WMC, Gray JAM, et al. Evidence based medicine: what it is and what it isn't. BMF 1996;312: 71-2.

15 Entwhistle VA, Watt IS, Bradbury R, et al. Media coverage of the child B case. BMF 1996;312:1587-91.

16 Gottlieb B. Non-organic disease in medical outpatients. Update 1969;5:917-22.

17 Speckens AEM, van Hemert AM, Spinhoven P, et al. Cognitive behavioural therapy for medically unexplained physical symptoms: a randomised controlled trial. BMF 1995;311: symptoms:

18 Mayou R. Medically unexplained physical symptoms. BMF 1991;303:534-5.

$19 \mathrm{McPherson} \mathrm{K}$. International differences in medical care practices. In: Health care systems in transition. OECD Social Policy Studies No 7 Paris: OECD, 1990;17-28.

20 Coulter A, Klassen A, McPherson K. How many hysterectomies should purchasers buy? Eur $\mathcal{F}$ Public Health 1995;5 123-9.

21 Bradlow J, Coulter A, Brooks P. Patterns of referral. Oxford: Health Services Research Unit, 1992.

22 Chimbira TH, Anderson ABM, Turnbull AC. Relation between measured menstrual blood loss and patients' subjective assessment of loss, duration of bleeding, number of sanitary towels used, uterine weight and endometrial surface area. Br f Obstet Gynaecol 1980;87:603-9.

23 Rees MCP. Role of menstrual blood loss in management of complaints of excessive menstrual bleeding. Br $\mathcal{F}$ Obste Gynaecol 1991;98:327-8.

24 Coulter A, Peto V, Jenkinson C. Quality of life and patient satisfaction following treatment for menorrhagia. Fam Pract 1994;11:394-401.

25 Lilford RJ. Hysterectomy: will it pay the bills in 2007? BMF 1997;314:160-1.

26 Coulter A, McPherson K. The hysterectomy debate. Quarterly fournal Social Affairs 1986;2:37996.

27 Portegijs PJM, Jeuken FMH, van der Horst FG, et al. A troubled youth: relations with somatization, depression and anxiety. Fam Pract 1996;13:1-11.

28 Katon W. Kleinman A, Rosen G. Depression and somatization: a review: Part 1. Am f Med 1982;72:127-35.

29 Hampton JR, Harrison MJG, Mitchell JRA, Prichard JS Seymour C. Relative contributions of history-taking, physi- cal examination, and laboratory investigation to diagnosis and management of medical outpatients. BMF 1975; ii: and man-

30 Peterson MC, Holbrook JH, Hales DV, et al. Contributions of the history, of physical examination, and of laboratory investigation in making medical diagnosis. Western $\mathcal{F} \mathrm{Med}$ 1992;156:163-5.

31 Byrne PS, Long BEL. Doctors talking to patients: a study of the verbal behaviour of general practitioners consulting in their surgeries. London: HMSO, 1976.

32 Wolf MH, Putnam SM, James SA, et al. The medical interview satisfaction scale: development of a scale to measure view satisfaction scale: development of a scale to measure
patient perceptions of physician behaviour. $\mathcal{F}$ Behavioural patient perceptions of

33 Baker R. The reliability and criterion validity of a measure of patients' satisfaction with their general practice. Fam Pract $1991 ; 8: 171$-7.

34 Kinnersley P, Stott N, Peters T, et al. A comparison of methods for measuring patient satisfaction with consultations in primary care. Fam Pract 1996;13:41-51.

35 Starfield B, Wray C, Hess K, et al. The influence of patientpractitioner agreement on outcome of care. Am $\mathcal{f}$ Public Health 1981;71:127-31.

36 Burack RC, Carpenter RR. The predictive value of the presenting complaint. $\mathcal{F}$ Fam Pract 1983;16:749-54.

37 Beckman HB, Frankel RM. The effect of physician Beckman HB, Frankel RM. The effect of physician
behaviour on the collection of data. Ann Intern Med 1984; 101:692-6.

38 Stewart MA, McWhinney IR, Buck CW. The doctor/patient relationship and its effect upon outcome. F $R$ Coll Gen Pract 1979;29:77-82.

39 Tuckett D, Boulton M, Olson C, Williams A. Meetings between experts: an approach to sharing ideas in medical consultations. London: Tavistock Publications, 1985.

40 Williams S, Weinman J, Dale J, Newman S. Patient expectations: what do primary care patients want from the GP and how far does meeting expectations affect patient satisfaction? Fam Pract 1995;12:193-201.

41 Hart JT. Innovative consultation time as a common European currency. Eur $\mathcal{f}$ Gen Pract 1995;1:34-7.

42 Savage R. Armstrong D. Effect of a general practitioner's Savage R. Armstrong D. Effect of a general practitioner's
consulting style on patients' satisfaction: a controlled study. BMF 1990;301:968-70.

43 Howie JGR, Porter AMD, Heaney DJ, Hopton JL. Long to short consultation ratio: a proxy measure of quality of care for general practice. Br $\mathcal{F}$ Gen Pract 1991;41:48-54.

44 Buchan IC, Richardson IM. Time study of consultations in general practice. Scottish Health Studies No 27. Edinburgh: Scottish Home \& Health Department 1973.

45 Department of Health. General medical practitioners' workload (survey 1989-1990). A report prepared for the Doctors' $\mathcal{E}$ Dentists' Review Body. London: Department of Health, 1991.

46 Ridsdale L. Evidence-based general practice: a critical reader. London: WB Saunders, 1995.

47 Smith R. Global competition in health care. BMF 1996;313: $764-5$.

48 Nicol $\mathrm{D}$. The managerial revolution: medicine as a business Med Educ 1995;29:413.

49 Smith R. Management in the NHS. BMF 1991;302: 1555-6.

50 Greenfield S, Kaplan SH, Ware JE, Yano EM, Frank JH Patients' participation in medical care. 7 Gen Intern Med 1988;3:448-57.

51 Kaplan SH, Greenfield S, Ware JE. Assessing the effects of physician-patients interactions on the outcomes of chronic disease. Med Care 1989;27:S1 10-27.

52 Vicinus M, Nergaard B, eds. Ever yours, Florence Nightingale: selected letters. London: Virago, 1989. 